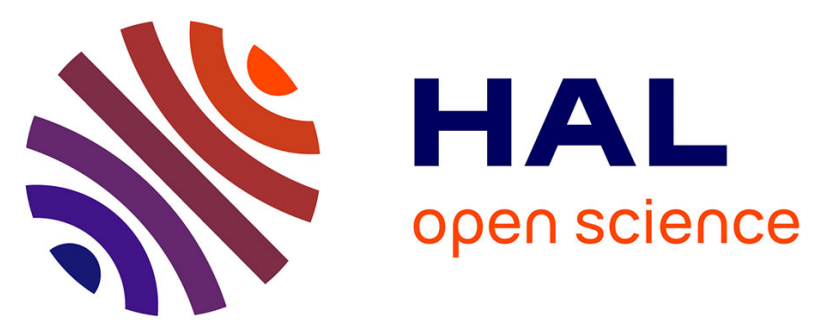

\title{
Thermal constraints on body size depend on the population position within the species' thermal range in temperate songbirds
}

Nicolas Dubos, Olivier Dehorter, Pierre-Yves Henry, Isabelle Le Viol

\section{- To cite this version:}

Nicolas Dubos, Olivier Dehorter, Pierre-Yves Henry, Isabelle Le Viol. Thermal constraints on body size depend on the population position within the species' thermal range in temperate songbirds. Global Ecology and Biogeography, 2019, 28 (2), pp.96-106. 10.1111/geb.12805 . hal-02307459

\section{HAL Id: hal-02307459 https: / hal.sorbonne-universite.fr/hal-02307459}

Submitted on 8 Oct 2019

HAL is a multi-disciplinary open access archive for the deposit and dissemination of scientific research documents, whether they are published or not. The documents may come from teaching and research institutions in France or abroad, or from public or private research centers.
L'archive ouverte pluridisciplinaire $\mathbf{H A L}$, est destinée au dépôt et à la diffusion de documents scientifiques de niveau recherche, publiés ou non, émanant des établissements d'enseignement et de recherche français ou étrangers, des laboratoires publics ou privés. 
archives-ouvertes

\section{Thermal constraints on body size depend on the population position within the species'}

Nicolas Dubos, Olivier Dehorter, Pierre-Yves Henry, Isabelle Le Viol

\section{To cite this version:}

Nicolas Dubos, Olivier Dehorter, Pierre-Yves Henry, Isabelle Le Viol. Thermal constraints on body size depend on the population position within the species'. Global Ecology and Biogeography, Wiley, 2019, 28 (2), pp.96-106. 10.1111/geb.12805 . hal-02307459

\section{HAL Id: hal-02307459 \\ https://hal.sorbonne-universite.fr/hal-02307459}

Submitted on 8 Oct 2019

HAL is a multi-disciplinary open access archive for the deposit and dissemination of scientific research documents, whether they are published or not. The documents may come from teaching and research institutions in France or abroad, or from public or private research centers.
L'archive ouverte pluridisciplinaire HAL, est destinée au dépôt et à la diffusion de documents scientifiques de niveau recherche, publiés ou non, émanant des établissements d'enseignement et de recherche français ou étrangers, des laboratoires publics ou privés. 
1 Thermal constraints on body size depend on the population position within the species'

2 thermal range in temperate songbirds

3

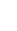

Nicolas Dubos, Olivier Dehorter, Pierre-Yves Henry, Isabelle Le Viol

Running title: Temperature effect on size along thermal range

\section{ABSTRACT}

Aim There is mounting evidence that climate warming can induce morphological changes locally, particularly size reduction. However, the direction of thermal stress may differ between climatic regions. We predicted that morphological response to temperature fluctuations should vary throughout species ranges, depending on the local climate. Hot temperature anomalies are expected to induce size reduction in hot regions where species live close to their upper thermal limit, whereas size stasis (or increase) would be expected in cold regions, where species live close to their lower thermal limit.

\section{Location France (204 sites)}

Time period 2000-2014 springs

Major taxa studied Songbird species $(n=9)$

Methods We tested whether the effect of temperature anomalies on juvenile body size varied along an $11^{\circ} \mathrm{C}$-thermal gradient.

Results In warmer springs, juveniles were larger overall at the coldest sites, but this effect decreased towards the hottest sites, becoming negative for 2 species.

Main conclusions Warming should induce body size increases more frequently at the cold edge of species distribution ranges, and rather body size declines at the hot edge. The climate- 
23 dependency of the effect of weather fluctuations on body size is still under-acknowledged,

24 and the pattern identified deserves to be investigated over broader climatic gradients and

25

26

27

28 Key words: Bergmann's rule, birds, climate warming, France, temperature anomaly, thermal range, wing length 
Although an increasing attention is given to body size change as a response to climate warming (Gardner et al., 2011), this phenomenon is still little documented and its underlying mechanisms are poorly understood. The effects of rising temperatures on animal structural size can be mediated through effects on juvenile growth and size-dependent mortality (Gardner et al., 2014). The original proposal was that body size would decline with warming as a result of the advantage of being smaller under warmer conditions. With a higher surfacevolume ratio, smaller individuals can dissipate body heat more efficiently than larger individuals, which is advantageous in warm climates, as stated in Bergmann's rule (Bergmann, 1847). With climate warming, larger individuals would increasingly suffer from hyperthermia, and a size reduction is a possible adaptive response enabling individuals to cope with increasingly warm conditions (Gardner et al., 2011).

The application of Bergman's rule to climate warming has received controversial evidence so far (Teplitsky \& Millien, 2014). Despite rising temperatures, many species have not exhibited any change in body size over time (Meiri et al., 2009; Kruuk et al., 2015), or the trend was opposite to the prediction, i.e. size increase (Björklund et al., 2014; Pérez et al., 2016). This may be related to the complexity of temperature and other climatic impacts on physiology and body size (Gardner et al., 2014). Temperature change can potentially have contradictory effects depending on which biological feature is affected (e.g., body growth versus survival), and which aspect of temperature change is regarded (e.g., mean temperature versus heat wave frequency). For instance, increasing mean temperatures may impact body growth positively (Gardner et al., 2014), which is contradictory with the proposal of an application of Bergmann's rule to climate warming (i.e., selection for smaller in warmer mean temperatures). Besides, heat waves may select for larger individuals as a result of a lower evaporative water loss, enabling them to better evade dehydration (Gardner et al., 2011). 
More importantly, the effect of temperature fluctuations probably differs between climatic regions. For instance, the physiological and ecological consequences of annual weather deviation are likely to depend on the average local climatic regime: in cool or cold regions (e.g., Collins et al., 2016; Pérez et al., 2016; Dubos et al., 2018), or during cool periods of the year (e.g., Gardner et al., 2014b), hot temperatures indeed affect body growth positively. In addition, events of extreme heat are also scarcer in temperate climates than in arid systems (Garcia et al., 2014). Observed body size variations are therefore expected to represent the response to fluctuations in average temperatures in temperate climates (Dubos et al., 2018), whereas the influence of extreme hot events is expected to be particularly strong in arid, semiarid and tropical climates (Holmgren et al., 2016; Gardner et al., 2017). In arid or semi-arid climates, larger individuals are expected to survive heat waves better, presumably because the smallest individuals show higher rates of evaporative water loss, and would be more exposed to dehydration and mortality during heat waves (McKechnie \& Wolf, 2010).

For the same species, temporal variation in body size can differ between sites (e.g., Meiri et al., 2009; Collins et al., 2017; Dubos et al., 2018). Within a species distribution range, populations are likely to have adapted locally to average meteorological conditions (e.g., Both $\&$ te Marvelde, 2007). Their response to changes in environmental conditions may therefore differ between the hottest and the coldest parts of their distribution range (Both \& te Marvelde, 2007; Socolar et al., 2017). This is the case for population trends of European birds: abundances decline towards the hot edge of their species distribution range, while they increase towards the cold edge (Jiguet et al., 2010). Differential responses to climate change were also observed in avian phenology, with advancements in egg laying near the cold edge but not near the warm one (depending on the species; Both \& te Marvelde, 2007). A similar pattern was found in the nesting success of Californian birds, with a positive effect of temperature anomaly towards the cold edge of species distributions, and a negative effect 
towards the warm edge (Socolar et al., 2017). Individuals living close to the hot edge of their species distribution range are the most threatened by climate warming, because they live close to their upper thermal limit already (Jiguet et al., 2010; Deutsch et al. 2008; Tewksbury et al. 2008; Socolar et al., 2017). Conversely, individuals living at the cold edge are more coldlimited and would even benefit from hot anomalies, as a result of a lower exposure to cold stress (Jiguet et al., 2006). Hence, across thermal ranges, the impact of climate warming on populations is expected to change gradually, and ranges from positive at the cold edge towards negative at the hot edge (Jiguet et al., 2010). The influence of thermal anomalies would therefore depend on the relative position of the population within the distribution range, even within the inner part of species thermal ranges. Although this variation of the effect of temperature anomalies across a species range is now well acknowledged for population trends (Jiguet et al., 2010), to our knowledge, it has not yet been investigated on body size responses to temperature changes.

Contrasting effects of temperature increase on body size across the thermal range are expected to occur through two main mechanisms: (i) direct, thermoregulatory costs, and (ii) indirect, ecological effects through ecosystem productivity (Yom-Tov \& Geffen, 2011) and temporally mismatched predator-prey interactions (Husby et al., 2011). Firstly, the ability to thermoregulate depends on morphology, and the thermal constraint affecting morphology is expected to depend on the local climate. For instance, in song sparrows (Melospiza melodia), selection for heat retention was found to prevail in a continental climate during winter (Danner \& Greenberg 2015), while for the same species, it was driven by heat dissipation in a Mediterranean climate during summer (Greenberg et al., 2012). In this case, the differential morphological change affecting thermoregulation was applied to bill size. However, this should also apply to structural size, as heat loss/conservation can depend on the size of body appendices (e.g., Allen's rule; Allen, 1877) as well as on structural size (e.g., Bergmann's 
rule). In cold or cool regions (e.g., temperate to polar), individuals may be larger in warmer years (Collins et al., 2016; Pérez et al., 2016; Dubos et al., 2018) when the cold constraint on growth is alleviated. Tissue growth increases with temperature in two ways: by accelerating biochemical reactions and metabolism (Gillooly et al., 2001), and by reducing the allocation of energy used for body heat maintenance (Kendeigh, 1969), so this energy can be reallocated to growth (Gillooly et al., 2001; Dawson et al., 2005). Nestling growth may also be indirectly facilitated by warmer temperatures through the reduced thermoregulary load for parents: parents can spend more time foraging to provision nestlings with food, and less time at the nest to maintain them warm (e.g., Socolar et al., 2017). In warmer regions (e.g., dry tropical and Mediterranean), the risk that a temperature increase reaches detrimental or sub-lethal levels is higher (Khaliq et al., 2014). Larger individuals may suffer more from increasing temperature, as interpreted with the application of Bergmann's rule to warming (Gardner et $a l .$, 2011). Secondly, body size depends on food availability during ontogeny. For secondary consumers, food availability depends on temperature-driven primary production (Yom-Tov \& Geffen, 2011). In temperate regions, precipitation is rarely limiting, and higher temperatures would increase invertebrate abundance, i.e. the main resource for nestling and fledgling songbirds (Bale et al., 2002; but see Carroll et al. 2015 for an opposite response in hygrophilic peatlands). In semi-arid systems, such as Mediterranean regions, invertebrate abundance is more constrained by drought, resulting from limited rainfall combined with high temperatures (Gardner et al., 2014). An increase in spring temperature may therefore result in larger body size in cool climates, whereas it could result in smaller body size in Mediterranean or dry tropical climates, in the case of co-occurrence with limited precipitation. Hence, direct and indirect effects of temporal variation in mean temperature on body size are expected to differ between the hottest and the coldest parts of the species ranges (Fig. 1). 
We assessed whether the effect of interannual variation in mean spring temperature on juvenile body size varies along a thermal gradient $\left(11.2^{\circ} \mathrm{C}\right.$ between the coldest and the hottest study sites; Fig. 1) in a temperate region (France) for nine songbird species. We predicted that, during hot springs (relative to the local average temperature), juveniles should be larger at the coldest sites, and smaller at the hottest sites (Fig. 1). In temperate climates, the tippingpoint of the effect of local temperature on body size sensitivity to temperature anomalies should depend on the position of populations within the species thermal ranges: the colder the location of a population, the more its growth should increase with temperature anomaly.

\section{METHODS}

\section{Bird survey}

We used individual records of songbirds caught during sessions of the French Constant bird ringing Effort Sites (CES) scheme, from 2000 to 2014 (Robinson et al., 2009; more information at http://crbpo.mnhn.fr, see 'STOC Capture'). Biometric data used in the present study were collected at 204 sites by 132 volunteer bird ringers, each site being monitored during 4.1 \pm 3.3 SD years (Dehorter \& CRBPO 2015). Each site was visited at least three times during the breeding season (average 3.6 $\pm 1.6 \mathrm{SD}$ ), from 15 May until 19 July. For a given site, number and location of mist-nets were kept constant throughout the years. Each captured individual was individually marked, identified to species and aged (juvenile for birds born during the ongoing breeding season; Svensson 1992). Most sites are located in shrublands, woodlands with dense understorey, or reedbeds (Eglington et al., 2015). Our survey encompassed three major types of climate based on the Köppen Geiger classification (Peel et al., 2007): subalpine (corresponding to the subarctic climate, Dfc), temperate oceanic $(\mathrm{Cfb})$, and hot-summer Mediterranean climates (Csa), with a thermal range of $11.2^{\circ} \mathrm{C}$ between 

the coldest $\left(8.4^{\circ} \mathrm{C}\right.$ on average) and the hottest sites $\left(19.6^{\circ} \mathrm{C}\right.$ on average; Fig. S1) during spring.

\section{Biometric data}

Wing length measurements were used as a proxy for body size (Gosler et al., 1998; data for supposedly better proxies of body size, such as tarsus or longuest feather lengths were not available, and body mass data conveyed an information on precipitation-dependancy of body condition rather than on temperature-dependancy of body size, see Dubos et al. 2018). We worked on post-fledgling juveniles only, because individual body size is determined during a short period of growth in small songbirds, taking place mainly during the nestling stage (c. 23 weeks), and continuing for a few weeks after fledging (Salewski et al., 2010; Yom-Tom \& Geffen 2011). When recaptures occurred (representing $10 \%$ of the data), we randomly selected one measurement per individual. In May-July, when captures took place, juvenile songbirds are still within a few kilometres from their birth site, and captured individuals can be assumed to have grown under the documented local climatic conditions. Adults were not considered as their wing length depends on multiple, confounding effects of climate throughout the life cycle (ontogeny, yearly molt and size-dependent mortality; Yom-Tom \& Geffen 2011; Gardner et al., 2014).

As small sample sizes and data sparseness can compromise the robustness of inferences (Yom-Tov \& Geffen, 2011), we decided to include data for only (i) species $\geq 1000$ measured individuals, and (ii) species.site.year sampling units with $\geq 10$ measured individuals (Table S1). Since the hypotheses to be tested required that population position within the species thermal ranges varied across sampling sites (i.e., gradient of 'northern' / core / 'southern' populations), we measured the proportion of each species' thermal range that was included in 
our study area. To do this, we relied on the population thermal coordinate (Jiguet et al., 2010), an index of the relative position of a given site, for a given species, within its European thermal range (Table S1; Fig S1). A population thermal coordinate is computed as the difference between the species thermal maximum (mean spring temperature of the hottest 5\% of European Atlas grid cell; Jiguet et al., 2010) and the average temperature of a given site, divided by the species thermal range $\left({ }^{\circ} \mathrm{C}\right)$. This index varies between 0 and 1 . Values close to 0 represent populations near the species thermal minimum; values closer to 1 are populations near the species thermal maximum. We discarded one species (Acrocephalus schoenobaenus), because the thermal gradient represented by the study sites was very narrow $\left(2.2^{\circ} \mathrm{C}\right.$ between the coldest and the hottest sites, representing less than $15 \%$ of the species thermal range). For the remaining species, a wider proportion of their thermal ranged was represented (minimum for Sylvia communis $=31 \%$, representing a thermal gradient of $4.2^{\circ}$; respectively, mean $=$ $58 \% \pm 13 \mathrm{SD}$ and $8.5^{\circ} \mathrm{C} \pm 2.3 \mathrm{SD}$ for all species in Table S1). For seven species, surveyed sites fell well within the species thermal range (and edges were not documented), whereas for two species (Long-tailed tit Aegithalos caudatus, Common chiffchaff Phylloscopus collybita), some sites corresponded the hot edge of their respective thermal ranges. According to habitat preference, one species is a reedbed specialist (Common reed-warbler Acrocephalus scirpaceus), whereas the eight others are shrubland / woodland generalists (Great tit Parus major, Eurasian Blue tit Cyanistes caeruleus, Eurasian blackcap Sylvia atricapilla, Common whitethroat Sylvia communis, Common chiffchaff, Long-tailed tit, Eurasian blackbird Turdus merula, and European robin Erithacus rubecula; cf. Table S1, Fig. S2). The final dataset included nine species, all living in relatively similar thermal niches, resulting in a total of 34101 juveniles measured (see details per species in Table S1).

\section{Climatic data}


203 We used daily mean temperature data, obtained from E-Obs (Haylock et al., 2008), and for

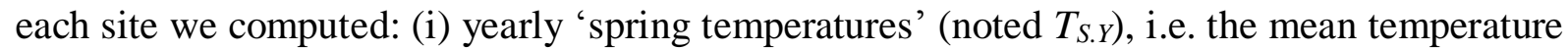
of a given year, at the site, for spring (from 1 April to 31 July, documenting between-year fluctuations of local thermal conditions), and (ii) 'local average temperature' (noted $T_{s}$ ), as the mean of $T_{S . Y}$ over the 2000-2014 period (documenting average or 'normal' thermal conditions at the geographical location of the capture site for the 1 April - 31 July period). Because species are expected to be adapted to local thermal conditions (c.f., Bergmann's rule; Ashton 2002), we analysed the interannual variation in body size in response to temperature variations using annual local temperature anomalies (instead of raw temperatures). Local temperature anomalies (noted $T A_{s t}$ ) were computed for each site as the difference between $T_{S}$ and $T_{S . Y .}$ Analysing the effects of temperature anomaly and local average temperature simultaneously, enables the respective effects of temporal $\left(T_{S . Y}\right)$ and spatial $\left(T_{S}\right)$ variations in thermal conditions on body size to be disentangled. Temperature anomaly and local average temperature were largely uncorrelated (Pearson's $r=0.007)$.

\section{Statistical analysis}

Using Linear Mixed Models (MCMCglmm; Hadfield, 2010), we assessed the effects of yearly temperature anomalies $T A_{s t}$ on the juvenile body size of our study species, and its interaction with the local average temperature $T_{s}$ (to assess whether the effect of $T A_{s t}$ varied along the species thermal range). We used uniform priors, with a burn-in of 20000 iterations, followed by an additional 100000 iterations for which posteriors were sampled with an interval of 100 .

We first built null models (Model 0 in Table 1) that included only adjustment variables, to verify that the inclusion of temperature variables enhanced the explanatory power. The null model, and all the following models (Table 1) accounted for the following sources of 
variation in wing length: (i) differences in mean size between species (fixed, factorial Species effect), (ii) species-specific post-fledgling growth throughout the season, using logtransformed Julian date (noted $\log ($ Date)) as a fixed, linear effect in interaction with species (Dubos et al., 2018), (iii) temperature-driven spatial differences between sites (e.g. Bergmann's rule) using a fixed, linear effect of local average temperature $T_{s}$, and (iv) speciesspecific dependence on local average temperature (fixed, factorial Species x $T_{s}$ interaction). This interaction term is justified by the fact that species may intrinsically respond differently to temperature (Ashton 2002), or may respond differently because the thermal ranges of the study species differ (e.g., for some species, French populations are located at the core of the thermal range, whereas for other species, French populations are closer to the species hot limit; Jarema et al., 2009). Consistent (v) between-observer, (vi) between-site and (vii) residual between-year variations were accounted for by random terms. Finally, (viii) comparative tests across species accounted for phylogenetic relatedness using pairwise phylogenetic distances. We extracted a set of 100 generated phylogenetic trees from Jetz et al., (2014) and integrated these using the 'pedigree' argument of the MCMCglmm function, that allows the portion of body size variation due to additive genetic variance to be disentangled from other sources of variance.

Then we built a set of models to assess the statistical support for our prediction. We first considered the dependence of wing length on temperature anomalies (linear, additive effect of $T A_{s t}$, Model 1). Then we accounted for the possibility that species respond differently (Jiguet et al., 2006) by adding the $T A_{s t} \times$ Species interaction term (Model 2). The dependence on temperature anomaly could differ along the observed thermal gradient; this was allowed for by adding the $T A_{s t} \times T_{s}$ interaction term to model 1 (Model 3). In addition, this hypothesis was assessed with a model that also accounted for the possibility that species response to $T A_{s t}$ differed between species (i. $e$. adding the $T A_{s t} \times T_{s}$ interaction to Model 2, resulting in Model 
4). Eventually, we allowed for species-specific relationships between temperature anomaly

$253 T A_{s t}$ and local average temperature $T_{s}$, by adding a $3^{\text {rd }}$-order interaction term between the effects of $T A_{s t}, T_{s}$ and species (Model 5). This model allows for a different direction and/or strength of both temperature effects between species. Model 5 results in the following formula:

Wing Length ${ }_{i s o t} \sim \alpha_{i}+\beta_{i 1} \cdot \log ($ Date $)+\beta_{i 2} . \mathrm{T}_{s}$

$$
+\beta_{3} \cdot \mathrm{TA}_{s t}+\beta_{i 3} \cdot \mathrm{TA}_{s t}+\beta_{4} \cdot\left(\mathrm{TA}_{s t} \times \mathrm{T}_{s}\right)+\beta_{i 4} \cdot\left(\mathrm{TA}_{s t} \times \mathrm{T}_{s}\right)
$$

$$
+\varepsilon_{s}+\varepsilon_{o}+\varepsilon_{t}+\varepsilon_{i s o t}
$$

where $\alpha_{i}$ is the average size of species $i$ (intercept), $\beta_{i 1}$ is the slope for the effect of logtransformed Date for species $i, \beta_{i 2}$ is the species-specific slope for the effect of local average temperature $\mathrm{T}_{\mathrm{s}}, \beta_{3}$ is the slope for the additive effect of temperature anomaly $\mathrm{TA}_{s t}, \beta_{i 3}$ is the species-specific deviation from $\beta_{3}$ (species interaction term), $\beta_{4}$ is the slope for the interaction between the effects of temperature anomaly $\mathrm{TA}_{s t}$ and local average temperature $\mathrm{T}_{s}, \beta_{i 4}$ is the species-specific deviation from $\beta_{4}$ (species interaction term), $\varepsilon_{s}, \varepsilon_{o}$ and $\varepsilon_{t}$ hold respectively for the random terms for site, observer and year effects, and $\varepsilon_{i s o t}$ is the residual variation.

The stepwise examination of predictions relied on the comparison of the six aforementioned models (Table 1), ranked on the basis of the Deviance Information Criterion (DIC, a Bayesian version of Akaike Information Criterion; Spiegelhalter et al., 2002). The model with the lowest value of DIC is considered to represent the best trade-off between parsimony and fit of the model to the data. Each model was fitted using 100 different phylogenetic trees, so that the average of all posteriors accounted for between-species phylogenetic dependence. All statistical analyses were performed under R version 3.3.0 (R Core Team, 2016). 


\section{RESULTS}

276

277

The body size response to temperature anomaly $\mathrm{TA}_{s t}$ differed between species. The model allowing for species-specific responses was better supported than the model assuming an additive response, common to all species (Model 2, Table 1). In accordance with our prediction, this response to $\mathrm{TA}_{s t}$ varied along thermal gradients (Model 4 and 5 received the highest statistical support; Table 1). The effect of temperature anomaly on body size depends on the local average temperature.

On average across species, at an intermediate site (i.e., for a mean local average temperature $\left.T_{s}=15.05^{\circ} \mathrm{C}\right)$ the higher the temperature anomaly, the longer the wing length $(+0.9 \mathrm{~mm}$ per ${ }^{\circ} \mathrm{C}$ anomaly; Model 3 in Table S2). But, the warmer the site (local average temperature, $T_{s}$ ), the lower the effect of temperature anomaly on wing length (for a $+1^{\circ} \mathrm{C}$ increase in local average temperature, the effect deceases by $0.052 \mathrm{~mm}$ per ${ }^{\circ} \mathrm{C}$ anomaly; Model 4 in Table S2). At the hottest sites, the effect of temperature anomaly was even reversed, with a potential decrease in wing length in the warmest years (Fig. 2). The nature of this 'temperature anomaly - by - local average temperature' interaction may differ between species, but these differences seem to be of minor importance in our dataset (since $\Delta \mathrm{DIC}$ is only 2 between models 4 and 5; Tables 1, S2). When plotting estimates for the interactive effects of $\mathrm{TA}_{\mathrm{st}}$ and $\mathrm{T}_{\mathrm{s}}$ per species (Fig. 3, S2), the response of body size is largely similar across species. Relying on model 5 , the three species showing a significantly positive effect of temperature anomaly at the coolest sites showed a significant interactive effect with local average temperature (i.e., Eurasian blackcap, long-tailed tit and great tit; Table S2). At the coolest sites (between 8.37 and $13.9^{\circ} \mathrm{C}$ depending on the species), body size increased significantly in warmer years for these species (respectively, by $0.86,1.71$ and $0.54 \mathrm{~mm}$ per ${ }^{\circ} \mathrm{C}$; Table 2). The temperature anomaly effect decreased when the local average temperature increased: for a $+1^{\circ} \mathrm{C}$ increase in local average temperature, the wing length of Eurasian blackcaps decreased by $-0.072 \mathrm{~mm}$ 
per ${ }^{\circ} \mathrm{C}$ of anomaly, $-0.324 \mathrm{~mm}$ per ${ }^{\circ} \mathrm{C}$ for long-tailed tits, and $-0.072 \mathrm{~mm}$ per ${ }^{\circ} \mathrm{C}$ for great tits (Table S2). This effect decreased enough to become negative for two species at the warmest sites (i.e., long-tailed tit: $-1.06 \mathrm{~mm}$ per ${ }^{\circ} \mathrm{C}$ of anomaly; European blackcap: $-0.29 \mathrm{~mm}$ per ${ }^{\circ} \mathrm{C}$ of anomaly at a site with an average temperature of $18.2^{\circ} \mathrm{C}$; Table 2 ; Fig. S3, S4). For these two species, the 'tipping-point' of local temperature, i.e. at which the sign of the effect of temperature anomaly changes, was located between the core and the hot edge of their respective thermal range (respectively for thermal coordinates of 0.77 and 0.70 ). For the great tit, the effect of temperature anomaly became null towards the hot edge of its thermal range (Table 2).

\section{DISCUSSION}

As expected in Figure 1, the response of body size to temperature anomaly depended on the position of populations within the species' thermal range. At the coldest sites, juveniles were larger in warmer years, but the size of those born at the warmest sites did not depend on spring temperature anomalies (or even declined in hot springs for some species).

The positive effect of temperature anomalies in cold regions may be related to both direct effects, through changes in thermoregulatory mechanisms, and indirect effects, through changes in food availability (Yom-Tov \& Geffen, 2011). Warmer years induce a reduction of the cost of body heat maintenance in cool areas, enabling a higher energetic allocation to body growth (Gillooly et al., 2001). An alternative, non-exclusive hypothesis is that warming may also increase net primary production, thus improving invertebrate abundance (Yom-Tov \& Geffen 2011; Dubos et al., 2018). In the present study, all study species are insectivorous during spring. Higher invertebrate abundance in some years may have enhanced juvenile protein intake, allowing them to reach larger fledgling sizes at the coolest sites (Lindström, 1999). 
The opposite effect, found for two species (long-tailed tits and Eurasian blackcaps) at the warmest sites, is consistent with the application of Bergmann's rule to climate warming (Gardner et al., 2011). The consequences of a local increase in temperature on individual fitness have been shown to differ between species of different latitudes in a previous study (Deutsch et al. 2008). At low latitudes, warming has more deleterious consequences on fitness than at higher latitudes. This is due to the fact that, at low latitudes (e.g., tropical), species live close to the upper boundary of their thermal tolerance, while high latitude species live farther from that lethal limit (Deutsch et al. 2008; Tewksbury et al. 2008). This process seems to apply at the intraspecific level, within species range. The negative effect of temperature anomaly on juvenile body size may be explained by two mechanisms. This may be the result of (1) a plastic response to environmental change on growth rates (Teplitsky \& Millien, 2014). Hotter years in warm areas would bring growing juveniles into suboptimal thermal conditions for juvenile growth (Mertens, 1977; Rodríguez \& Barba, 2016), which would result in smaller individuals. Size declines in hotter years could also be the result of (2) sizedependent mortality: the largest individuals would suffer the most from hyperthermia, and be more likely to die in warm years. However, lethal temperatures are rarely reached in temperate regions (mean number of days $>35^{\circ} \mathrm{C}=0.13 \pm 0.28 \mathrm{SD}$ days per spring at our study sites). Hence, from the present dataset, even at the hottest sites, a higher mortality in larger individuals in hot years would not be expected in France. Most studies attempting to find a selection for smaller size failed, or found the opposite pattern (Gardner et al., 2014; Dunn et al., 2016). The hypothesis of a cold constraint release for juvenile growth in hotter years is therefore the most likely in temperate climates. Our results are consistent with Danner and Greenberg (2005), suggesting that in temperate species, morphology is constrained by cold towards the coldest edge of their distribution range - and potentially across most of their temperate distribution range (i.e. not all individuals achieve optimal body size) - whereas at 
the hottest edge, heat (or drought-driven food shortage) would be the predominating constraint. An additional hypothesis is that very high temperatures could reduce parental foraging efficiency, e.g. due to physiological stress (hyperthermia, water loss) enhanced by reduced invertebrate activity (Geiser et al., 2008; Cunningham et al., 2013). Lower parental feeding frequency could affect offspring growth rate, and result in smaller fledglings (Searcy et al., 2004).

The indirect effects of temperature anomaly on ecosystem production - and therefore food availability - at the hottest sites may also differ from the coldest sites. In semi-arid environments, net primary production depends on precipitation to a greater extent than temperature (e.g., Gardner et al., 2014; Holmgren et al., 2016). This may apply to the French Mediterranean region, as both climates are similar (see www.worldclimate.com). Hence, it is unlikely that temperature response is driven by changes in net primary production at the warmest study sites, which may explain the decreasing effect of temperature anomaly towards the hottest sites. Another hypothesis is that, because temperature change can impact food web structures (e.g., Edeline et al., 2013), a differential effect can be the consequence of differing changes in the biotic environment. The effect of temperature change on body size, through changes in food availability in ecosystems, may therefore depend on the regional climate and ecosystems, regardless of the population position within the species thermal range. These antagonistic or synergistic effects of local temperature, precipitation and ecosystem structures on individual body size deserve to be investigated in future research.

Body size response to warming may depend on the average climate under which the local population evolved, as found for temporal trends in population size (Jiguet et al., 2010). The consequences of climate warming on populations are often more deleterious at the hot edge of species distribution, while it can be favourable at the cold edge (Parmesan \& Yohe, 2003; Hickling et al., 2006; Leroy et al., 2014), with a linear graded response in between (Jiguet et 
al., 2010). Although the present analysis included a relatively wide range of thermal conditions $\left(>11^{\circ} \mathrm{C}\right)$, the number of sites represented in cold and hot regions was limited (Fig. S1). We used species for which the distribution edges are not (or rarely) included in our study area (Fig. S2). Despite species response to warming which may be stronger at the edges of their distribution range (Jarema et al., 2009), we still detected a differential response along a fragment of their range. Moreover, while responses to warming are expected to be greater in thermal specialists (i.e., species with a narrow thermal range compared to other Palearctic species; Jiguet et al., 2006), our results were obtained from species that are mostly thermal generalists (i.e., with a wide thermal range; Table S1). This suggests that differential effects of temperature change on body size may apply to a wide range of species (including thermal generalists), which is consistent with results obtained for population trends (Jiguet et al., 2010). In spite of geographic and taxonomic limits, the pattern revealed is the one expected theoretically (cf. abundance, phenology patterns), and we provide the first evidence for a structured effect of temperature on body size. Studies performed at large geographic scale, aiming at testing the effect of temperature variation on body size - while assuming a uniform effect - may therefore fail to detect an effect of temperature change because it may be blurred by opposing effects between sites.

The estimated effect sizes for the influence of temperature anomaly on body size are small, ranging from -0.8 to $1.0 \%$ of species' mean wing length per Celsius degree of annual anomaly. Compared to spatial effects of temperature (i.e., local average temperature; cf. Bergmann's rule), these effects sizes were of similar magnitude ( -0.23 to $0.16 \%$ per Celsius degree; Table S2). In other studies focussing on temporal variation in bird size, the effect of mean temperature of the breeding period was about $1 \%$ of the juvenile wing length in Australia (Gardner et al. 2014), and the effect of summer temperature ranged between -0.63 and $0.15 \%$ per Celsius degree in eastern North America (Collins et al., 2017). Formerly, 
Dubos et al. (2018) have even clarified that, when analysing additive effects of annual

401

402

403

404

405 weather on wing length across sites and species, they could explain 5\% of the total variance in juvenile wing length at best, i.e. the additive and specie-specific variation between years. All the remaining variance actually corresponds to site-specific annual variations (7\%) or siteand species-specific annual variations (88\%). Hence, we acknowledge that effect sizes are indeed small, and that this questions the biological relevance of the corresponding size changes. This concern about small size effects applies to most existing studies on short-term body size changes, and is a recurrent issue in ecology (Møller \& Jennions, 2002). Given the multiple determinants of body size, it even appears obvious that body size cannot drastically change between years and generations. Hence, whatever the influence of the environment on juvenile body size, it will always be restricted to a narrow range of change of average size, beyond which other compensatory mechanisms start to play (e.g. offspring mortality, early termination of growth). We are not aware of a statistical framework, applicable to existing data, which would allow to objectively qualifying the biological relevance of the observed, statistically robust effects of temperature on wing length.

In the present study, we focussed on spring temperatures because this corresponds to the period of body growth, as body size has been shown to be mainly driven by the conditions during this period (Yom-Tov Geffen, 2011), and because in songbirds, body growth ends soon after fledging (some weeks). However, high temperatures may drive size-dependent mortality in juveniles, as they are more exposed to hypo- or hypertheremia than their parents (Mertens, 1977). In addition, size-dependent mortality can also affect adults (Gardner et al., 2014), and mortality can occur at later stages of individuals' life (i.e., carry-over effects; van de Pol \& Cockburn, 2011). Getting the full picture of body size responses to temperature will require to investigate its effects during other parts of the year (e.g., winter, when bird mortality is the highest in temperate climates; Van Balen, 1980), at different time-scales 
(Kruuk et al., 2015), and include assessments of size-dependent mortality (e.g., using markrecapture approaches).

427

To conclude, the differential effect of climate warming along species range already found in species distributions (Hickling et al., 2006), phenological shifts (Both \& te Marvelde, 2007) and population trends (Jiguet et al., 2010) also applies to body size. We predict that climate warming would induce body size increases (up to optimal body size) more frequently at the cold edge of species distribution ranges, and body size declines would be more likely at the hot edge. In France, the impact of warming on avian population dynamics may impact body size negatively at the warmest sites, corresponding to the Mediterranean region, where species (including our study species) live closer to the upper boundary of their thermal tolerance (Jiguet et al., 2010). As individual fitness is often size-dependant, with the largest surviving and/or reproducing better (Lindström 1999; Ronget et al., 2017), it is to be feared that size decline may impact populations negatively. To assess the robustness and generality of our conclusions, future studies should investigate the synergistic effects of local temperature anomalies (weather fluctuations) and local average temperatures (climate) on body size across a larger number of species (including a broader spectrum of life-history traits, and particularly more thermal specialists), and across a broader climatic range, to include the entire thermal ranges of the species studied. Another challenge for future studies on the link between body size and temperature fluctuations will be to sort out the proximate mechanisms at play (e.g. ontogeny versus mortality, and thermal versus trophic pressure). 


\section{REFERENCES}

447

448

449

450

451

452

453

454

455

456

457

458

459

460

461

462

463

464

465

466

467

468

469

Allen, J.A. (1877) The influence of physical conditions in the genesis of species. Radical Review, 1, 108-140.

Ashton, K.G. (2002) Patterns of within-species body size variation of birds : strong evidence for Bergmann's rule. Global Ecology and Biogeography, 11, 505-523.

Bale, J.S., Masters, G.J., Hodkinson, I.D., Awmack, C., Bezemer, T.M., Brown, V.K., Butterfield, J., Buse, A., Coulson, J.C., Farrar, J., Good, J.E.G., Harrington, R., Hartley, S., Jones, T.H., Lindroth, R.L., Press, M.C., Symrnioudis, I., Watt, A.D. \& Whittaker, J.B. (2002) Herbivory in global climate change research: Direct effects of rising temperature on insect herbivores. Global Change Biology, 8, 1-16.

Van Balen, J.H. (1980) Population Fluctuations of the Great Tit and Feeding Conditions in Winter. Ardea, 68, 143-164.

Bergmann, C. (1847) Uber die Verhaltnisse der Warmeokonomie der Thiere zu ihrer Grosse, Göttinger. Göttingen.

Björklund, M., Borras, A., Cabrera, J. \& Senar, J.C. (2014) Increase in body size is correlated to warmer winters in a passerine bird as inferred from time series data. Ecology and Evolution, 59-72.

Both, C. \& te Marvelde, L. (2007) Climate change and timing of avian breeding and migration throughout Europe. Climate Research, 35, 93-105.

Collins, M.D., Relyea, G.E., Blustein, E.C. \& Badami, S.M. (2017) Heterogeneous changes in avian body size across and within species. Journal of Ornithology, 158, 39-52.

Cunningham, S.J., Martin, R.O., Hojem, C.L. \& Hockey, P.A.R. (2013) Temperatures in Excess of Critical Thresholds Threaten Nestling Growth and Survival in A RapidlyWarming Arid Savanna: A Study of Common Fiscals. PLoS ONE, 8. 
Danner, R.M. \& Greenberg, R. (2015) A critical season approach to Allen's rule: bill size declines with winter temperature in a cold temperate environment. Journal of Biogeography, 42, 114-120.

Dawson, R.D., Lawrie, Æ.C.C. \& Brien, E.L.O. (2005) The importance of microclimate variation in determining size, growth and survival of avian offspring : experimental evidence from a cavity nesting passerine. Oecologia, 144, 499-507.

Dehorter, O. \& CRBPO (2017) Bird ringing and movement database for France.

Deutsch, C.A., Tewksbury, J.J., Huey, R.B., Sheldon, K.S., Ghalambor, C.K., Haak, D.C. \& Martin, P.R. (2008) Impacts of climate warming on terrestrial ectotherms across latitude. Proceedings of the National Academy of Sciences of the United States of America, 105, $6668-6672$.

Dubos, N., Viol, I. Le, Robert, A., Teplitsky, C., Ghislain, M., Dehorter, O., Julliard, R. \& Henry, P.-Y. (2018) Disentangling the effects of spring anomalies in climate and net primary production on body size of temperate songbirds. Ecography.

Dunn, J.C., Hamer, K.C. \& Benton, T.I.M.G. (2016) Dynamics of phenotypic change : wing length declines in a resident farmland passerine despite survival advantage of longer wings. 152-157.

Edeline, E., Lacroix, G., Delire, C., Poulet, N. \& Legendre, S. (2013) Ecological emergence of thermal clines in body size. Global change biology, 19, 3062-8.

Eglington, S.M., Julliard, R., Gargallo, G., van der Jeugd, H.P., Pearce-Higgins, J.W., Baillie, S.R. \& Robinson, R.A. (2015) Latitudinal gradients in the productivity of European migrant warblers have not shifted northwards during a period of climate change. Global Ecology and Biogeography, 24, 427-436.

Garcia, R. a, Cabeza, M., Rahbek, C. \& Araújo, M.B. (2014) Multiple dimensions of climate change and their implications for biodiversity. Science (New York, N.Y.), 344, 1247579. 
Gardner, J.L., Peters, A., Kearney, M.R., Joseph, L. \& Heinsohn, R. (2011) Declining body size: a third universal response to warming? Trends in ecology \& evolution, 26, 285-91.

Gardner, J.L., Rowley, E., Rebeira, P. De, Rebeira, A. De, Brouwer, L. \& Gardner, J.L. (2017) Effects of extreme weather on two sympatric Australian passerine bird species. Philosophical Transactions of the Royal Society B: Biological Sciences, 372, 20160148.

Geiser, S., Arlettaz, R. \& Schaub, M. (2008) Impact of weather variation on feeding behaviour, nestling growth and brood survival in Wrynecks Jynx torquilla. Journal of Ornithology, 149, 597-606.

Gillooly, J.F., Brown, J.H., West, G.B., Savage, V.M. \& Charnov, L. (2001) Effects of Size and Temperature on Metabolic Rate. Science (New York, N.Y.), 293, 2248-2251.

Gosler, a. G., Greenwood, J.J.D., Baker, J.K. \& Davidson, N.C. (1998) The field determination of body size and condition in passerines: a report to the British Ringing Committee. Bird Study, 45, 92-103.

Greenberg, R., Cadena, V., Danner, R.M. \& Tattersall, G. (2012) Heat loss may explain bill size differences between birds occupying different habitats. PLOS ONE, 7, 1-9.

Hadfield, J.D. (2010) MCMC methods for multi-respoinse generalized linear mixed models: The MCMCglmm R package. Journal of Statistical Software, 33, 1-22.

Haylock, M.R., Hofstra, N., Klein Tank, a. M.G., Klok, E.J., Jones, P.D. \& New, M. (2008) A European daily high-resolution gridded data set of surface temperature and precipitation for 1950-2006. Journal of Geophysical Research, 113, D20119.

Hickling, R., Roy, D.B., Hill, J.K., Fox, R. \& Thomas, C.D. (2006) The distributions of a wide range of taxonomic groups are expanding polewards. Global Change Biology, 12, $450-455$.

Holmgren, M., Stapp, P., Dickman, C.R., Gracia, C., Graham, S., Gutiérrez, J.R., Hice, C., Jaksic, F., Kelt, D.A., Letnic, M., López, B.C., Meserve, P.L., Milstead, W.B., Polis, 

G.A., Andrea, M., Richter, M., Sabaté, S. \& Squeo, F.A. (2016) Extreme Climatic Events Shape Arid and Semiarid Ecosystems. Frontiers in Ecology and the Environment, 4, 87-95.

Husby, A., Hille, S.M. \& Visser, M.E. (2011) Testing mechanisms of Bergmann's rule: phenotypic decline but no genetic change in body size in three passerine bird populations. The American naturalist, 178, 202-213.

Jarema, J., Samson, J., McGill, B.I. \& Murray, M.H. (2009) Variation in abundance across a species' range predicts climate change responses in the range interior will exceed those at the edge : a case study with North American beaver. Global Change Biology, 15, 508522.

Jetz, W., Thomas, G.H., Joy, J.B., Redding, D.W., Hartmann, K. \& Mooers, A.O. (2014) Global Distribution and Conservation of Evolutionary Distinctness in Birds. Current Biology, 24, 919-930.

Jiguet, F., Devictor, V., Ottvall, R., Van Turnhout, C., Van der Jeugd, H. \& Lindström, A. (2010) Bird population trends are linearly affected by climate change along species thermal ranges. Proceedings of the Royal Society B: Biological Sciences, 277, 3601-8.

Jiguet, F., Julliard, R., Thomas, C.D., Dehorter, O., Newson, S.E. \& Couvet, D. (2006) Thermal range predicts bird population resilience to extreme high temperatures. Ecology letters, 9, 1321-30.

Kendeigh, C. (1969) Tolerance of Cold and Bergmann's Rule. The Auk, 86, 13-25.

Khaliq, I., Hof, C., Prinzinger, R., Böhning-Gaese, K. \& Pfenninger, M. (2014) Global variation in thermal tolerances and vulnerability of endotherms to climate change. Proceedings. Biological sciences / The Royal Society, 281, 20141097.

Kruuk, L.E.B., Osmond, H.L. \& Cockburn, A. (2015) Contrasting effects of climate on juvenile body size in a Southern Hemisphere passerine bird. Global Change Biology, 21, 
Leroy, B., Bellard, C., Dubos, N., Colliot, A., Vasseur, M., Courtial, C., Bakkenes, M., Canard, A. \& Ysnel, F. (2014) Forecasted climate and land use changes, and protected areas: the contrasting case of spiders. Diversity and Distributions, 20, 686-697.

Lindström, J. (1999) Early development and fitness in birds and mammals. Trends in Ecology and Evolution, 14, 343-348.

McKechnie, A.E. \& Wolf, B.O. (2010) Climate change increases the likelihood of catastrophic avian mortality events during extreme heat waves. Biology letters, 6, 253256.

Meiri, S., Guy, D., Dayan, T. \& Simberloff, D. (2009) Global change and carnivore body size: data are stasis. Global Ecology and Biogeography, 18, 240-247.

Mertens, J.A.L. (1977) Thermal conditions for successful breeding in Great Tits (Parus major L.) - I. Relation of growth and development of temperature regulation in nestling great tits. Oecologia, 28, 1-29.

Møller, A.P. \& Jennions, M.D. (2002) How much variance can be explained by ecologists and evolutionary biologists? Oecologia, 132, 492-500.

Parmesan, C. \& Yohe, G. (2003) A globally coherent fingerprint of climate change impacts across natural systems. Nature, 421, 37-42.

Peel, M.C., Finlayson, B.L. \& McMahon, T.A. (2007) Updated world map of the KöppenGeiger climate classification. Hydrology and Earth System Sciences Discussions, 4, 439473.

Pérez, J.H., Krause, J.S., Chmura, H.E., Bowman, S., McGuigan, M., Asmus, A.L., Meddle, S.L., Hunt, K.E., Gough, L., Boelman, N.T. \& Wingfield, J.C. (2016) Nestling growth rates in relation to food abundance and weather in the Arctic. The Auk, 133, 261-272. van de Pol, M. \& Cockburn, A. (2011) Identifying the critical climatic time window that 

affects trait expression. The American naturalist, 177, 698-707.

571 R Core Team (2016) R: A language and environment for statistical computing. R Foundation

572

573 for Statistical Computing.

Rodríguez, S. \& Barba, E. (2016) Nestling growth is impaired by heat stress: An experimental study in a mediterranean great tit population. Zoological Studies, 55.

Ronget, V., Gaillard, J.M., Coulson, T., Garratt, M., Gueyffier, F., Lega, J.C. \& Lemaître, J.F. (2017) Causes and consequences of variation in offspring body mass: Meta-analyses in birds and mammals. Biological Reviews, 93, 1-27.

Salewski, V., Hochachka, W.M. \& Fiedler, W. (2010) Global warming and Bergmann's rule: do central European passerines adjust their body size to rising temperatures? Oecologia, $162,247-60$.

Searcy, W.A., Peters, S. \& Nowicki, S. (2004) Effects of early nutrition on growth rate and adult size in song sparrows Melospiza melodia. Journal of Avian Biology, 35, 269-279.

Socolar, J.B., Epanchin, P.N., Beissinger, S.R. \& Tingley, M.W. (2017) Phenological shifts conserve thermal niches in North American birds and reshape expectations for climatedriven range shifts. Proceedings of the National Academy of Sciences, 114, 201705897.

Spiegelhalter, D.J., Best, N.G. \& Carlin, B.P. (2002) Bayesian measures of model complexity and fit. J. R. Statist. Soc. B, 64, 583-639.

Svensson, L. (1992) Identification guide to European passerines, Märstatryc. Stockholm. Teplitsky, C. \& Millien, V. (2014) Climate warming and Bergmann's rule through time: is there any evidence? Evolutionary applications, 7, 156-68.

Tewksbury, J.J., Huey, R.B. \& Deutsch, C.A. (2008) Putting the Heat on Tropical Animals The Scale of Prediction. Science (New York, N.Y.), 320, 1296-1297.

Yom-Tov, Y. \& Geffen, E. (2011) Recent spatial and temporal changes in body size of terrestrial vertebrates: probable causes and pitfalls. Biological Reviews, 86, 531-41. 
596 DATA ACCESSIBILITY: The dataset used in this analysis is available as an R object in 597 supporting information. 
598 Table 1 Set of models used to assess the relationship between juvenile wing length, local 599 temperature anomaly, local average temperature and species identity. The lowest Deviance 600 Information Criterion (DIC) indicates the 'best' model (in bold), and $\triangle \mathrm{DIC}$ is the DIC 601 difference with the best model. TA $s t$ holds for the local temperature anomalies for a site $s$ in 602 year $t$, during the breeding season. $\mathrm{T}_{s}$ is the average temperature for a site $s$ across the 20006032014 breeding seasons. All models included the same adjustment variables (see text). Based 604 on DIC, Models 4 and 5 received similar statistical support.

\begin{tabular}{llcc}
\hline Model & Model description & DIC & $\Delta$ DIC \\
\hline M0 & Species $+\mathrm{T}_{s}+$ Species $\times \mathrm{T}_{s}$ & 150879 & 28 \\
& + other adjustment var. (see text) & & \\
M1 & M0 + $\mathrm{TA}_{s t}$ & 150878 & 27 \\
M2 & M1 $+\mathrm{TA}_{s t} \times$ Species & 150860 & 9 \\
M3 & M1 $+\mathrm{TA}_{s t} \times \mathrm{T}_{s}$ & 150869 & 18 \\
M4 & M2 $+\mathrm{TA}_{s t} \times \mathrm{T}_{s}$ & $\mathbf{1 5 0 8 5 1}$ & $\mathbf{2}$ \\
M5 & M4 $+\mathrm{TA}_{s t} \times \mathrm{T}_{s} \times$ Species & $\mathbf{1 5 0 8 4 9}$ & $\mathbf{0}$
\end{tabular}

605

606 
Table 2 Estimates of Temperature anomaly $\left(\mathrm{TA}_{s t}\right)$ at the observed coldest $\left(\mathrm{T}_{s} \mathrm{~min}\right)$ and hottest

$608\left(\mathrm{~T}_{s} \max \right)$ species-specific study sites, and the local average temperature $\left(\mathrm{T}_{s}\right)$ where the

609 temperature anomaly effect is predicted to reverse (i.e., is null). Numbers in parentheses

610 indicate the corresponding thermal coordinate (a value of 0 represents the coldest sites where

611 the species can be present, and 1 represents the hottest sites; Table S1). Predicted values were

612 obtained from MCMCglmm posterior estimates (Model 5 in Table 1) and accounted for

613 phylogenetic relatedness (species are sorted accordingly).

\begin{tabular}{|c|c|c|c|c|c|c|c|}
\hline \multirow[b]{2}{*}{ Species } & \multirow{2}{*}{$\begin{array}{c}\mathrm{T}_{s} \min \\
\left({ }^{\circ} \mathrm{C}\right)\end{array}$} & \multicolumn{2}{|c|}{$\mathrm{TA}_{s t}$ effect at $\mathrm{T}_{s} \min$} & \multirow{2}{*}{$\begin{array}{c}\mathrm{T}_{s} \max \\
\left({ }^{\circ} \mathrm{C}\right)\end{array}$} & \multicolumn{2}{|c|}{$\mathrm{TA}_{s t}$ effect at $\mathrm{T}_{s} \max$} & \multirow{2}{*}{$\begin{array}{c}\mathrm{T}_{\mathrm{s}}\left({ }^{\circ} \mathrm{C}\right) \text { at } \\
\text { null } \\
\text { TA effect }\end{array}$} \\
\hline & & $\begin{array}{l}\text { Slope } \\
\left(\mathrm{mm} .{ }^{\circ} \mathrm{C}^{-1}\right)\end{array}$ & $\begin{array}{l}\% \text { of wing } \\
\text { length }\end{array}$ & & $\begin{array}{l}\text { Slope } \\
\left(\mathrm{mm} .{ }^{\circ} \mathrm{C}^{-1}\right)\end{array}$ & $\begin{array}{l}\% \text { of wing } \\
\text { length }\end{array}$ & \\
\hline Parus major & 13.2 & 0.54 & 1.0 & 19.6 & -0.02 & -0.3 & $20.9(1.00)$ \\
\hline Parus caeruleus & 11.0 & -0.25 & -0.8 & 19.6 & 0.22 & 0.2 & 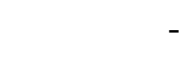 \\
\hline Acrocephalus scirpaceus & 8.4 & -0.13 & -0.7 & 18.8 & 0.39 & 0.1 & - \\
\hline Sylvia atricapilla & 8.5 & 0.86 & 0.5 & 18.2 & -0.29 & -0.3 & $15.1(0.70)$ \\
\hline Sylvia communis & 12.0 & 0.28 & 0.7 & 19.6 & -0.15 & -0.3 & $15.1(0.79)$ \\
\hline Phylloscopus collybita & 11.4 & 0.12 & 0.8 & 18.2 & 0.12 & 0.2 & 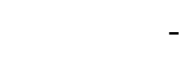 \\
\hline Aegithalos caudatus & 8.4 & 1.71 & 0.9 & 18.2 & -1.06 & -0.1 & $16.4(0.77)$ \\
\hline Turdus merula & 13.9 & 0.68 & 0.3 & 18.2 & -0.39 & -0.4 & $12.3(0.60)$ \\
\hline Erithacus rubecula & 8.4 & 0.16 & 0.6 & 18.0 & 0.13 & 0.2 & - \\
\hline
\end{tabular}

614 

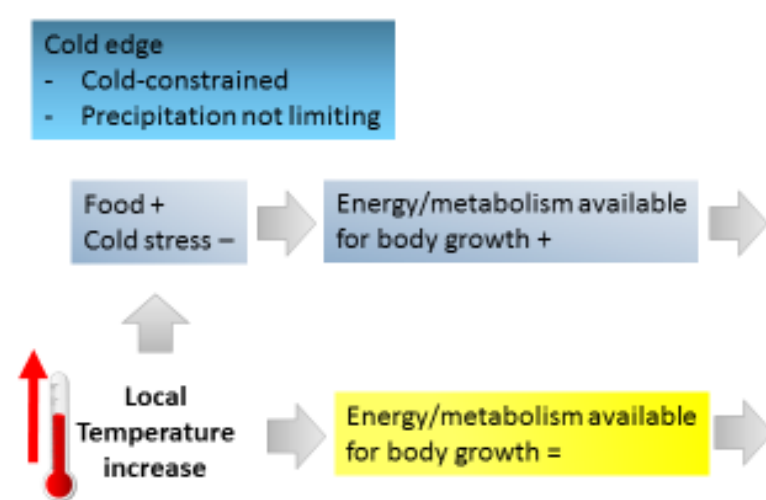

Energy/metabolism available for body growth $=$

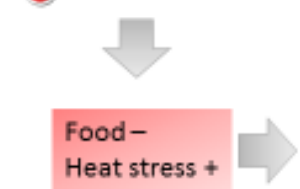

Energy/metabolism available for body growth -

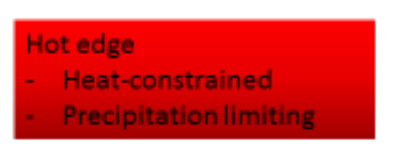

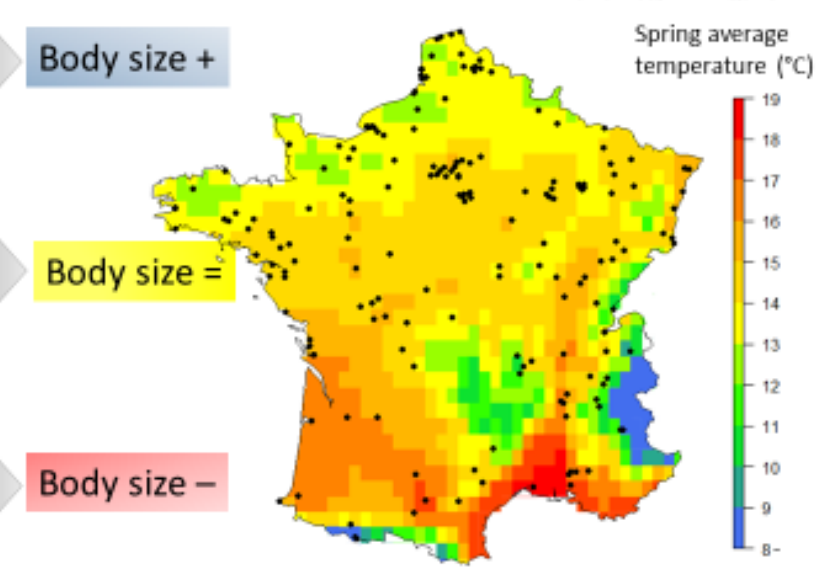

617

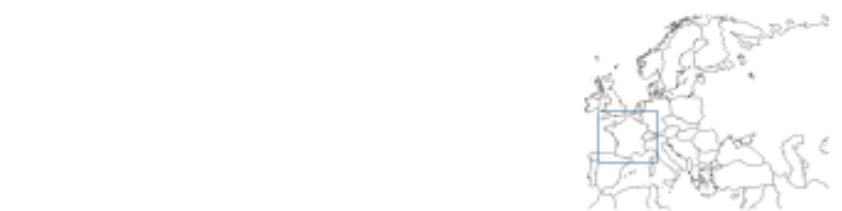

618 Fig. 1 Theoretical framework for a differential effect of climate warming on body size

619 depending on local climate (here, spring average temperatures). At hot sites (red, dark orange,

620 including the Mediterranean region), positive temperature anomalies are predicted to induce

621 body size reduction, whereas at cool sites (blue-green, including mountain regions), body size

622 enlargement is expected. The map shows the distribution of the 204 study sites in France. 


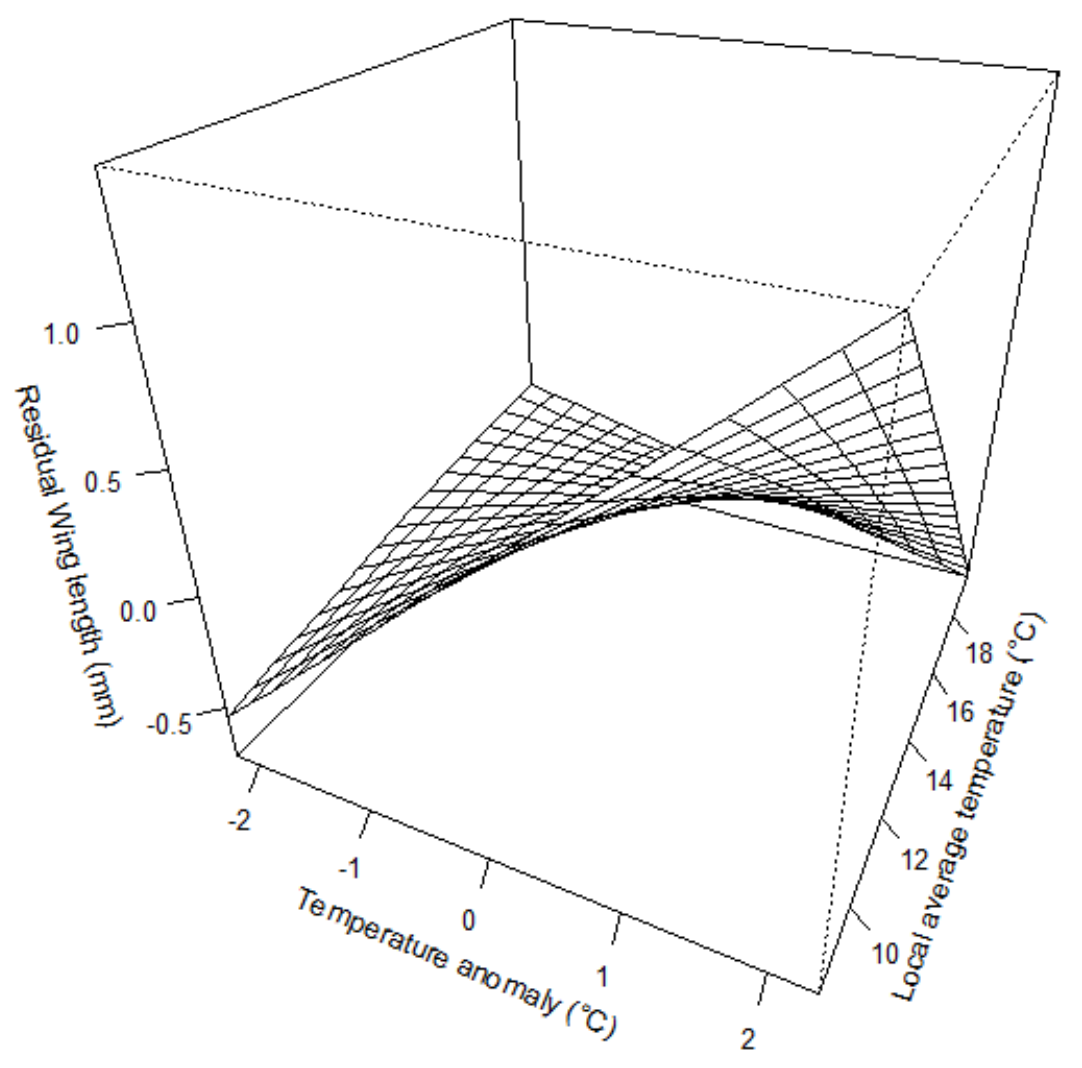

624

625 Fig. 2 Residual response of average juvenile wing length to temperature anomaly along a

626 gradient in average local temperature, for nine breeding songbird species from France.

627 Predicted values were obtained from MCMCglmm (Model 3, see text and Table 1). Local

628 average temperature is the mean spring temperature of a given site for the period 2000-2014.

629 Wing length was centred on the mean value per species. Species-specific predicted values are 630 shown in supporting information (Fig. S3). 

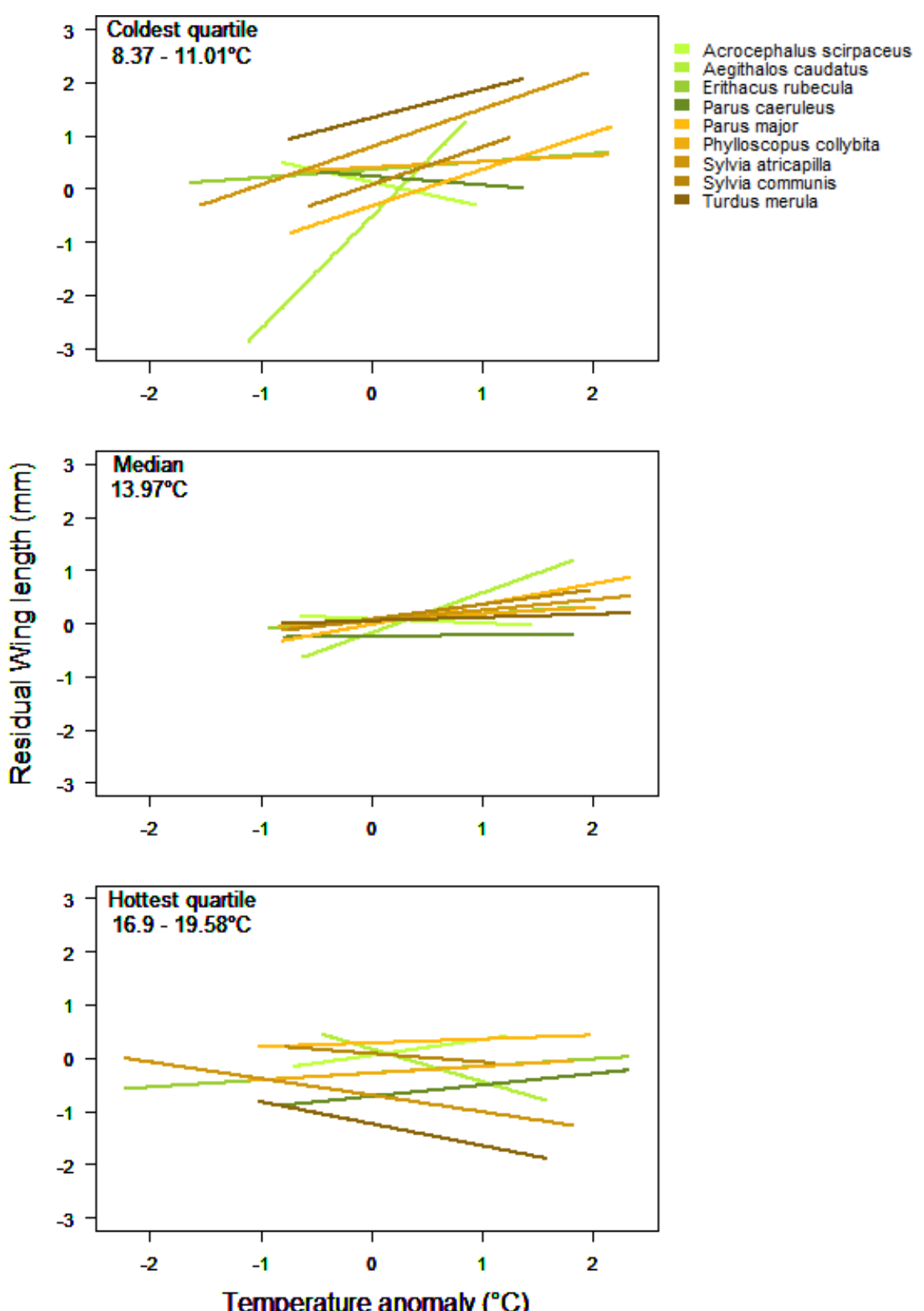

633 Fig. 3 Species-specific response of juvenile wing length to spring temperature anomaly, 634 separated into three quantiles of local average temperature, for nine breeding songbirds 635 species from France. Predicted values were obtained from MCMCglmm (Model 5, Table 1). 636 Wing length was centred on species means. Local average temperature is the mean spring temperature of a given site for the period 2000-2014. Coldest quartile: average response at the $63825 \%$, coldest sites $(\mathrm{n}=9)$; Median quartiles: average response at the $25-75 \%$ intermediate 639 sites $(n=180)$; Hottest quartile: average response at the $75 \%$ hottest sites $(n=15)$. 